\title{
Pleural Neoplasm
}

National Cancer Institute

\section{Source}

National Cancer Institute. Pleural Neoplasm. NCI Thesaurus. Code C3332.

A benign or malignant neoplasm that involves the serous membrane that lines the lungs and thoracic cavity. Most pleural neoplasms are metastatic. Diffuse malignant mesothelioma is the most common primary malignant neoplasm of the pleura. 